University of Nebraska - Lincoln

DigitalCommons@University of Nebraska - Lincoln

Papers in the Earth and Atmospheric Sciences

Earth and Atmospheric Sciences, Department

\title{
Progressive abandonment and planform changes of the central Platte River in Nebraska, central USA, over historical timeframes
}

John D. Horn

University of Nebraska-Lincoln, john.horn@huskers.unl.edu

R. Matthew Joeckel

University of Nebraska-Lincoln, rjoeckel3@unl.edu

Christopher R. Fielding

University of Nebraska-Lincoln, cfielding2@unl.edu

Follow this and additional works at: https://digitalcommons.unl.edu/geosciencefacpub

Part of the Earth Sciences Commons

Horn, John D.; Joeckel, R. Matthew; and Fielding, Christopher R., "Progressive abandonment and planform changes of the central Platte River in Nebraska, central USA, over historical timeframes" (2012). Papers in the Earth and Atmospheric Sciences. 317.

https://digitalcommons.unl.edu/geosciencefacpub/317

This Article is brought to you for free and open access by the Earth and Atmospheric Sciences, Department of at DigitalCommons@University of Nebraska - Lincoln. It has been accepted for inclusion in Papers in the Earth and Atmospheric Sciences by an authorized administrator of DigitalCommons@University of Nebraska - Lincoln. 


\title{
Progressive abandonment and planform changes of the central Platte River in Nebraska, central USA, over historical timeframes
}

\author{
J. D. Horn, ${ }^{1}$ R. M. Joeckel, ${ }^{1,2}$, and C. R. Fielding ${ }^{1}$ \\ 1. Department of Geosciences, University of Nebraska-Lincoln, Lincoln, NE 68588-0340, USA \\ 2. School of Natural Resources, University of Nebraska-Lincoln, Lincoln, NE 68583-0996, USA \\ Corresponding author - J. D. Horn, tel 816 604-3132, email john.horn@huskers.unl.edu
}

\begin{abstract}
This paper presents data compiled from aerial photography, General Land Office maps (GLOs), and discharge data from the central Platte River in Nebraska that quantify and provide a new understanding of channel evolution and abandonment in a braided stream. Analyses of aerial photographs and GLOs in ArcMap ${ }^{\mathrm{TM}}$ show that channel area decreased by an average of 46\% from 1938 to 2006 and that channel widths in 1858 were an average of 539\% greater than in 2006. Annual discharge during 1942-2006 does not show a clear long-term relationship with the decrease in channel width and area. Rather, stabilization through vegetation of bars and channel banks is cited as the major contributing factor to channel shrinkage and the development of an anabranching system within the boundaries of the 1858 channel. The stabilization of anabranches and the encroachment of vegetation onto banks, abandoned channels, and islands have significantly impacted the riparian ecosystem as mobile sandy bars gradually disappeared. Annual aerial photographs of the Platte River from 1984 to 2001 show that the river responds to year-to-year changes in mean discharge through the formation and disappearance of in-channel features such as medium-size transverse bars, large transverse bars, open channels, exposed channel surfaces, laterally accreted surfaces, and vegetated channel islands. Vegetated channel islands and stable anabranches also increased during 1984-2009. Significant change has also occurred since the beginning of the twentieth century on the Wood River, a local tributary to the Platte River. The Wood River experienced a long-term increase in sinuosity after it occupied the abandoned North Channel of the Platte River, which last experienced major sediment transport $350 \pm 50$ years ago, according to an optically stimulated luminescence date. The modern Wood River is also superimposed on a prehistoric meandering pattern with significantly greater meander amplitude.

We present the first channel abandonment model to account for the gradual abandonment of the Platte River braided stream system and its evolution from a braided to an anabranching system: in stage 1, the channel prominently features macroform bars comprising downstream-migrating foresets; in stage 2, downstream-migrating dunes are deposited over channel bed features; and in stage 3, there is a shift from a braided stream to a stream dominated by anabranches and only channel bed features (e.g., three-dimensional dunes) are present. Our new model characterizes the features expected to be found in abandoned braided channels, as well as more temporary features that form and are destroyed through successive stages of abandonment.
\end{abstract}

Keywords: braided, anabranching, Platte, channel, abandonment, channel narrowing

\section{Introduction}

The central Platte River near Grand Island, NE (Figure 1), has undergone radical change in channel planform since the first detailed survey of the area in 1858. Much of its channel area has been abandoned and encroached upon by riparian vegetation; and its channel banks, as well as many of its islands, have been stabilized by vegetation. The modern Platte River is affected by dams and diversion canals (Figure 1b), which have been shown to restrict sediment influx and discharge (Murphy et al., 2004). Additionally, the stretch of the Platte River that flows through the study area receives no signif- icant discharge or sediment influx from tributaries. The remarkable short-term evolution of the central Platte River from an open, braided condition to a stream with multiple, stable anabranches and heavily vegetated banks and islands has significantly impacted the riparian ecosystem through the gradual disappearance of mobile sandy bars. Migrating birds, such as the whooping crane and piping plover (which depend on such open sandy areas for feeding) and the effect of fluvialsystem change on threatened and endangered species is a major environmental concern (National Academy of Sciences, 2004). The goal of our study is to compile data from several sources, including aerial photography, General Land Office 
(a)
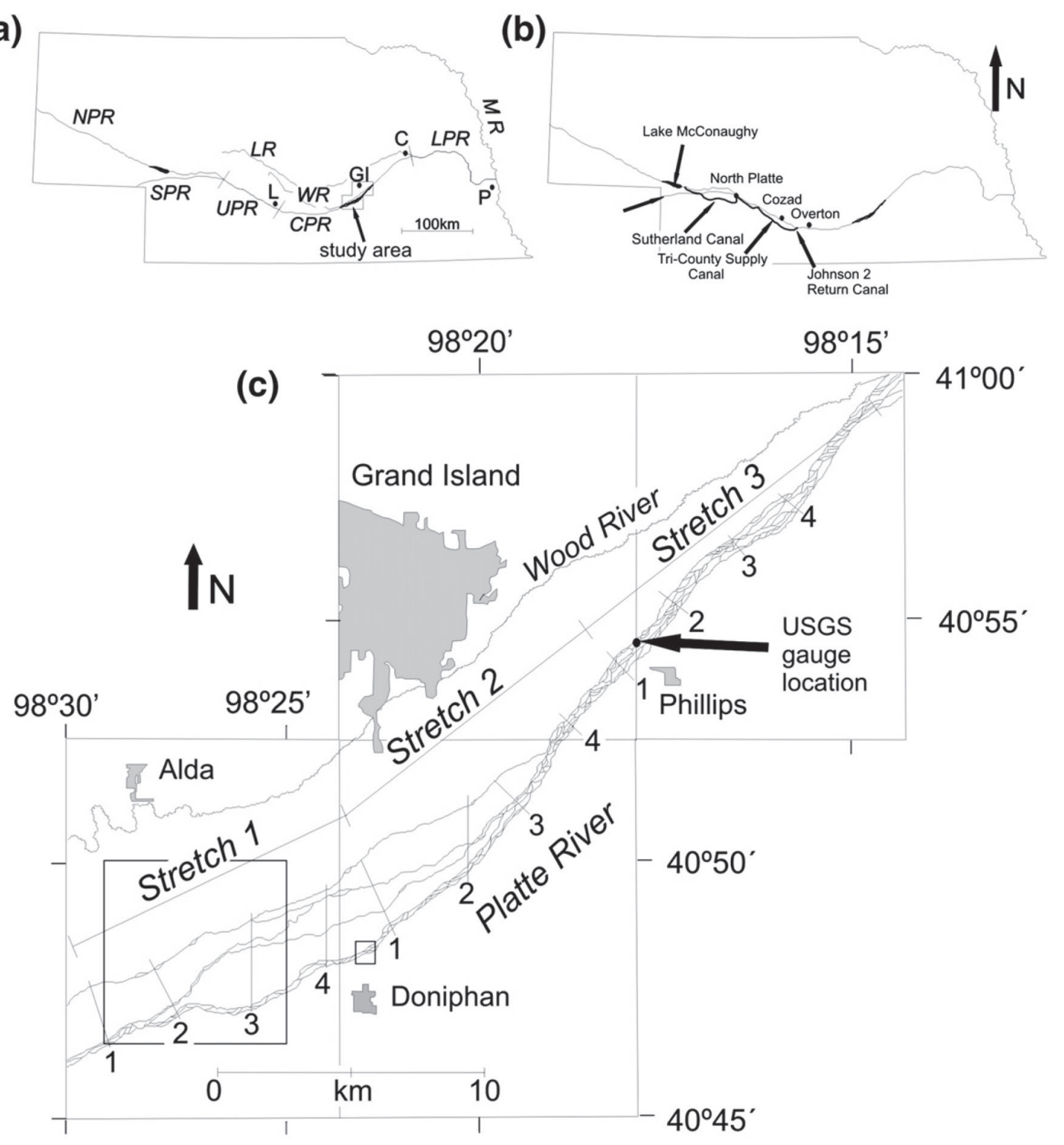

Figure 1. a) and b) Maps showing location of geographic features mentioned in the text. NPR - North Platte River, SPR - South Platte River, UPR - upper Platte River, CPR - central Platte River, LPR - lower Platte River, LR - Loup River, WR - Wood River, GI - Grand Island, C Columbus, P - Plattsmouth. c) Map showing the study area entailing the central Platte River and Wood River near Grand Island, Nebraska. The study area includes the Alda, Doniphan, Grand Island, and Phillips 1:24,000 USGS quadrangle maps. The Platte River in this area has multiple anabranches and the Wood River is meandering. The map includes section lines used to measure channel width at different time intervals from 1938 to 2006. Section lines (numbered) were drawn and measured perpendicular to the channel. Arrow points to USGS gauge station used for discharge data. Squares outline location of Figure 2a (larger square) and B (smaller square).

Maps (GLOs), and discharge data in order to quantify the evolution of a progressively abandoned braided stream system. Our documentation of the detailed sequence of events that constituted the evolution of the Platte River during historical times is also an important contribution to the understanding of regional ecosystem change.

Assessments of changes in planform and bank conditions on the Platte River have typically utilized historical maps and aerial photography (e.g., Williams, 1978; Johnson, 1994; Johnson and Boettcher, 1999; Joeckel and Henebry, 2008), as does this study. In the previous studies, however, the resolution of time was comparatively coarse because the primary sources of data were aerial photographs of the Platte River taken at intervals of 5-17 years. The present study, in contrast, examines a 26-year annual time series (1984-2009) of aerial photographs, in addition to historical maps and aerial photographs from 1938 to 1951 . Beyond the contributions that this study makes toward understanding historical ecosystem change, the exam- ination of an annual time series provides a new and more detailed perspective on braided-stream channel constriction and planform change, and it also yields novel insights into the evolution of macroforms in a sandy braided stream that can be applied to studies of ancient stream systems.

\section{Materials and methods}

Three stretches of the Platte River near Grand Island, NE, were chosen for this study (Figure 1): stretch 1 has several long-lived anabranches, which are defined by Bridge (2003) as channel segments independent from one another in terms of flow and sediment transport (Figures 1 \& 2a); stretch 2 transitions from several anabranching channels upstream to a few larger channels with newer anabranches downstream (Figures $1 \& 2 b$ ); and stretch 3 contains a single channel (Figure 1). We distinguish types of anabranches in the forthcoming section. 
(a)
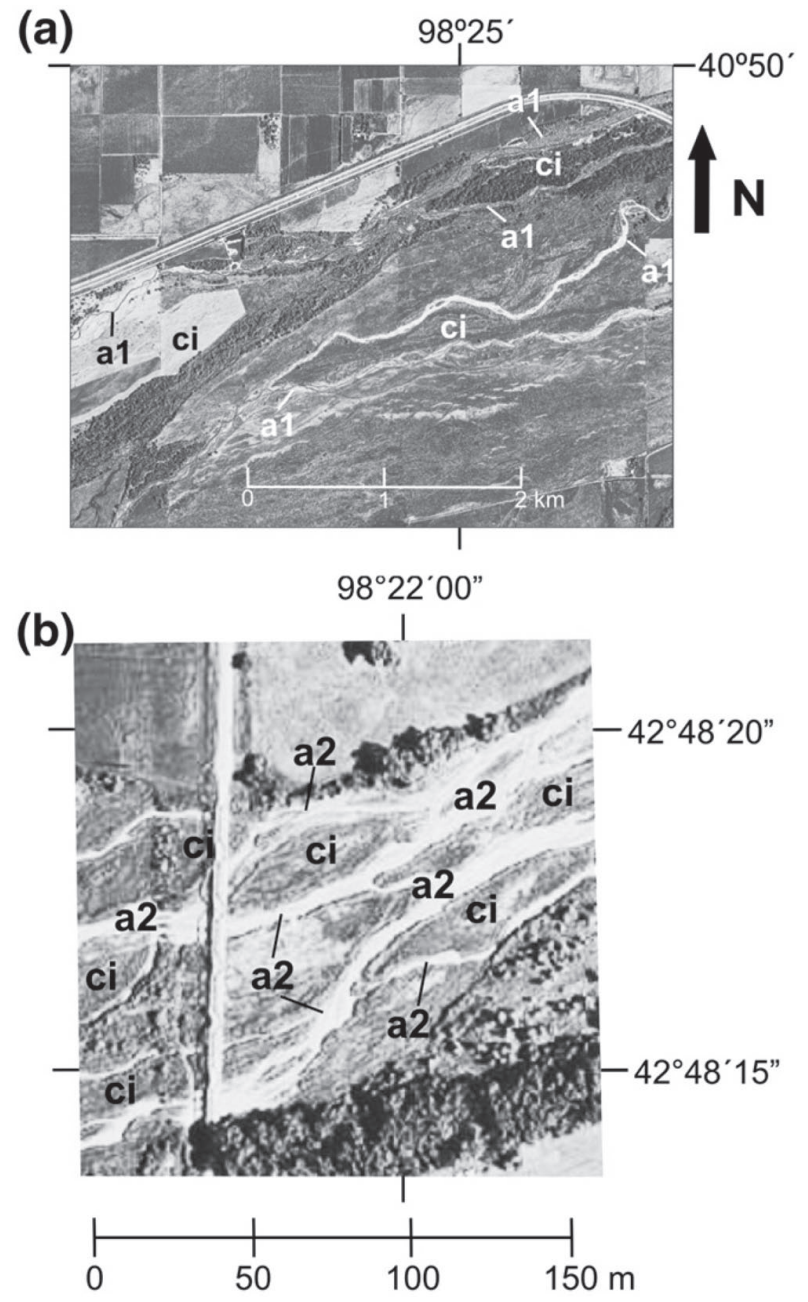

Figure 2. a) Partial aerial coverage of first-order anabranches. a1 represents first-order anabranches. ci represents vegetated channel islands. (b) Partial aerial coverage of second-order anabranches $\sim 5 \mathrm{~km}$ south of Grand Island: a2 represents second-order anabranches.

Longer term channel changes along the Platte and Wood Rivers were quantified using the following steps described below. (i) We scanned 1938 and 1951 aerial stereophotographs, General Land Office maps (GLOs) from 1858 to 1866, and Digital Orthoquadrangles (DOQQs) from 1993 to 2006, and georeferenced them in ArcMap ${ }^{\mathrm{TM}}$ to produce composite images. (ii) We then measured widths of the active channel from these images in the GIS environment. (iii) Vegetated islands were isolated from the channel by clipping the channel polygon along borders of the islands at a rendering of 1:10,000, and edited at a scale of 1:5000. (iv) Changes in channel area were compared over the different time intervals (1938-2006) by creating GIS shapefiles outlining the active channels for each time interval. (v) Point-to-point channel widths were measured along transects at 3-km intervals (Figure 1) and at a scale of 1:5000 for individual years during the period 1858-2006.

Anastomosing channels, in places separated from the main flow of the river for tens of kilometers, which are present in both the nineteenth-century GLOs and in aerial photographs, are considered to be long-lived (Figure 2a). For statistical analysis, these anabranches are designated "first-order anabranches" and are collectively measured as single channels separated by channel islands, as per Joeckel and Henebry (2008). The term "second-order anabranches" (Figure 2b) refers to the smaller, secondary channels within the braided stream formed because of post-1940s stabilization of channel bars into islands by vegetation that render individual chan- nels immobile. Both first- and second-order streams were accounted for in quantifying changes in channel width and area in long-term channel evolution.

We also assessed shorter term changes in the Platte River through the examination of a 26-year annual time series (19842009) of aerial photographs taken by the U.S. Department of Agriculture Farm Service Agency (FSA) during June or July of each year. Two subareas were chosen for this higher resolution study (Figure 3). The widths of active channels were measured at points where vegetated islands are absent (Figure 3). The FSA aerial imagery was scanned from slides, georeferenced, and overlain on DOQQs using ArcMap ${ }^{\mathrm{TM}}$. Each layer was analyzed by calculating channel area using methods as described above, measuring channel cross sections every $100 \mathrm{~m}$, and by comparing the vegetated islands and unvegetated bars to imagery taken during previous and subsequent years. Collection and analysis of these data were carried out in conjunction with surficial mapping of the alluvial valley of the Platte River and ground penetrating radar investigations of active central Platte River braid bars (Horn et al., in press) within the same study area.

\section{Results}

\subsection{Longer term (1858-2006) channel evolution of Platte River}

The western portion of the central Platte River comprises several anabranches, which are separated by vegetated islands as much as several tens of kilometers in length. Within the central Platte River, anabranches of two scales were recognized within the main channel.

Channel widths in the Platte River decreased overall from 1858 to 2006. However, change in width has not been consistent during this time interval or between different channel sections. Width decreased steadily along stretch 1-1 and stretch 1-2 (Figure 4c) after 1938 continued until the present. Other sections on stretch 1 that are dominated by first-order anabranches decreased steadily from 1938 to 1993, but increased slightly between 1993 and 1999, a period during which record-high annual flows were recorded (Figure 4c). Stretches 2 and 3, which have the largest percentage of second-order anabranches (Figure 4d and e), showed little change from 2003 to 2006, the latter being a very low flow year. The differences between channel widths during the period from 1858 to 2006 were as great as $1570 \%$, while the average change in widths was $539 \%$. The most constant decrease in channel width and area from the 1858-2006 occurred along stretch 1, which mainly comprised of first-order anabranches, and is attributed to the gradual encroachment of vegetation along the margins of channels and subsequent lateral accretion. In contrast, stretches 2 and 3 experienced more variance caused by the appearance of multiple stable channel islands, resulting in the establishment of functional anabranches.

Along the central Platte River, channel area decreased by an average of $46 \%$ from 1938 to 2006 . On a smaller time interval, a short-term increase in channel area from 1993 to 1999 reflects a significant increase in mean annual discharge from 52 to $91 \mathrm{~m}^{3} / \mathrm{s}$. This increase, in turn, reflects the remobilization of exposed channel bedforms and vegetated islands into medium and large transverse bars (Figure 4). Low discharge rates during 2005-2006 (Figure 4a) of $1 \mathrm{~m}^{3} / \mathrm{s}$ promoted an increase in bar stabilization that decreased channel area by $45 \%$ from 1999. Despite a 182\% higher mean discharge rate in 1999 $\left(80 \mathrm{~m}^{3} / \mathrm{s}\right)$ as compared to $1951\left(50 \mathrm{~m}^{3} / \mathrm{s}\right.$, Figure $\left.5 \mathrm{a}\right)$, channel area decreased by $27 \%$ over this time interval (Figure $4 \mathrm{~b}$ ).

\subsection{Longer term (1938-1999) channel evolution of Wood River}

Optically-stimulated luminescence (OSL) age dating indicates that the north channel of the Platte River (Figure 5) oc- 


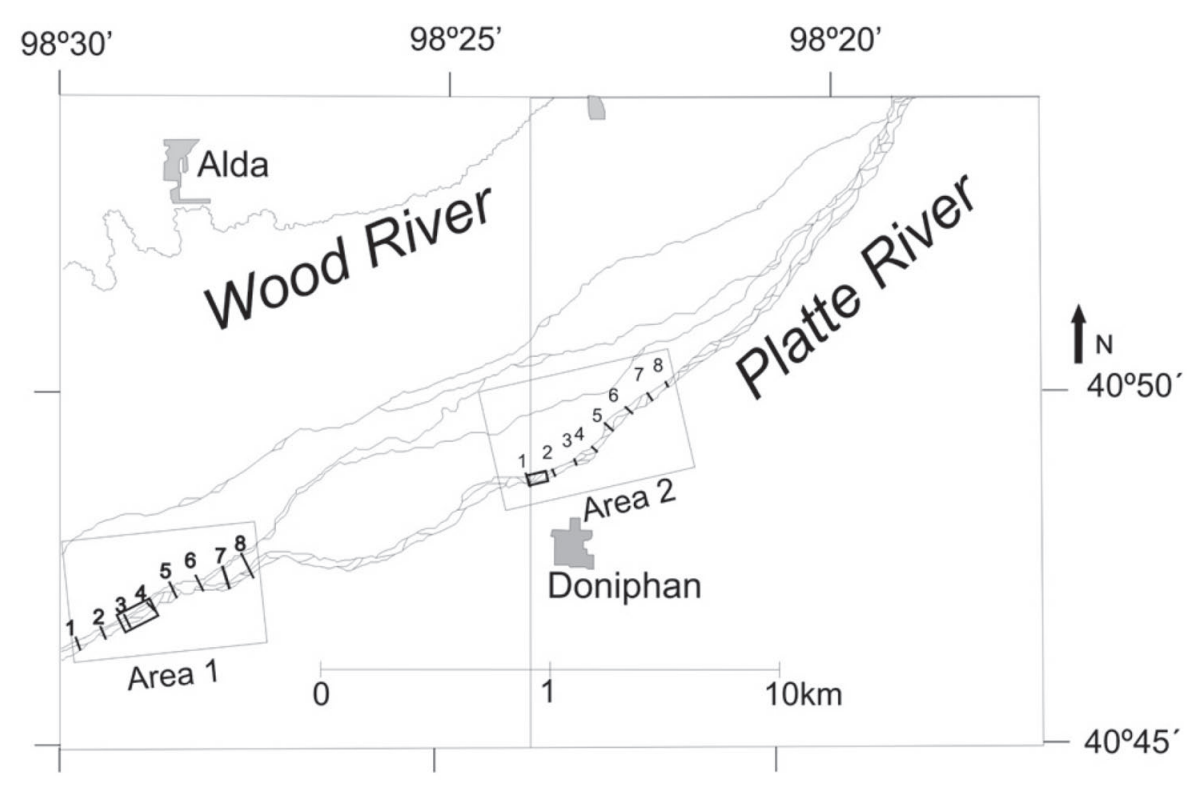

Figure 3. Location of study areas used to measure annual channel change. Section lines were used to measure channel widths at different time periods. Area 1 is located upstream and represents a first order anabranch. Area 2 is located in a single-channel portion of the stream. The black rectangles within each study area represent the areas used to chronicle channel feature change over time (see Figures $9 \& 10$ ).

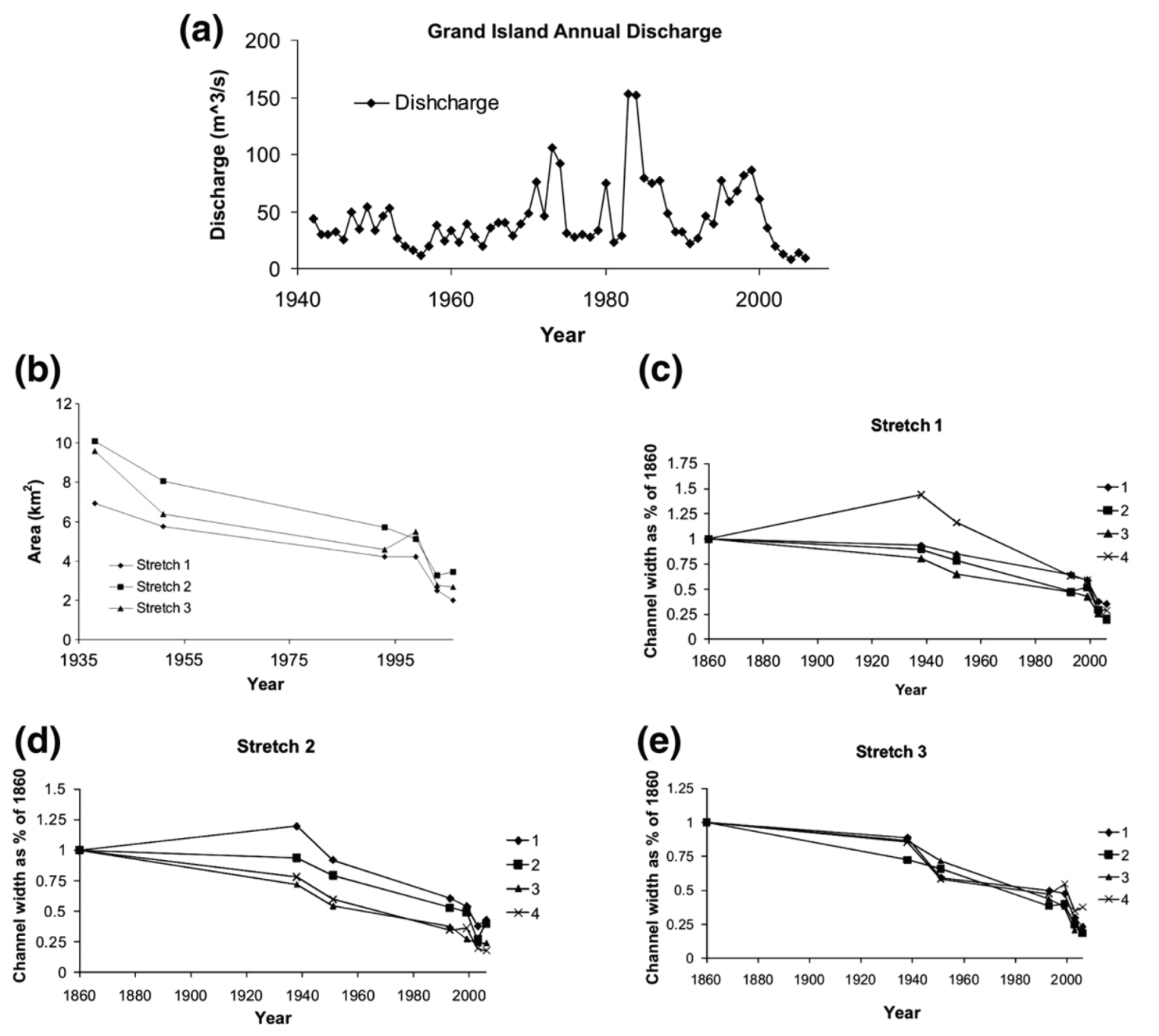

Figure 4. a) Discharge of the Platte River within the western part of the Grand Island section of the study area shows a strongly bimodal pattern from 1970 to present. b) Channel area shows an overall decrease over time. c, d, and e) Variance of channel width measurements of the three stretches as a percentage of channel width in the 1860s. With the exception of a general increase in 1999 and outliers in 2006, channel widths have exhibited a steady decrease. 

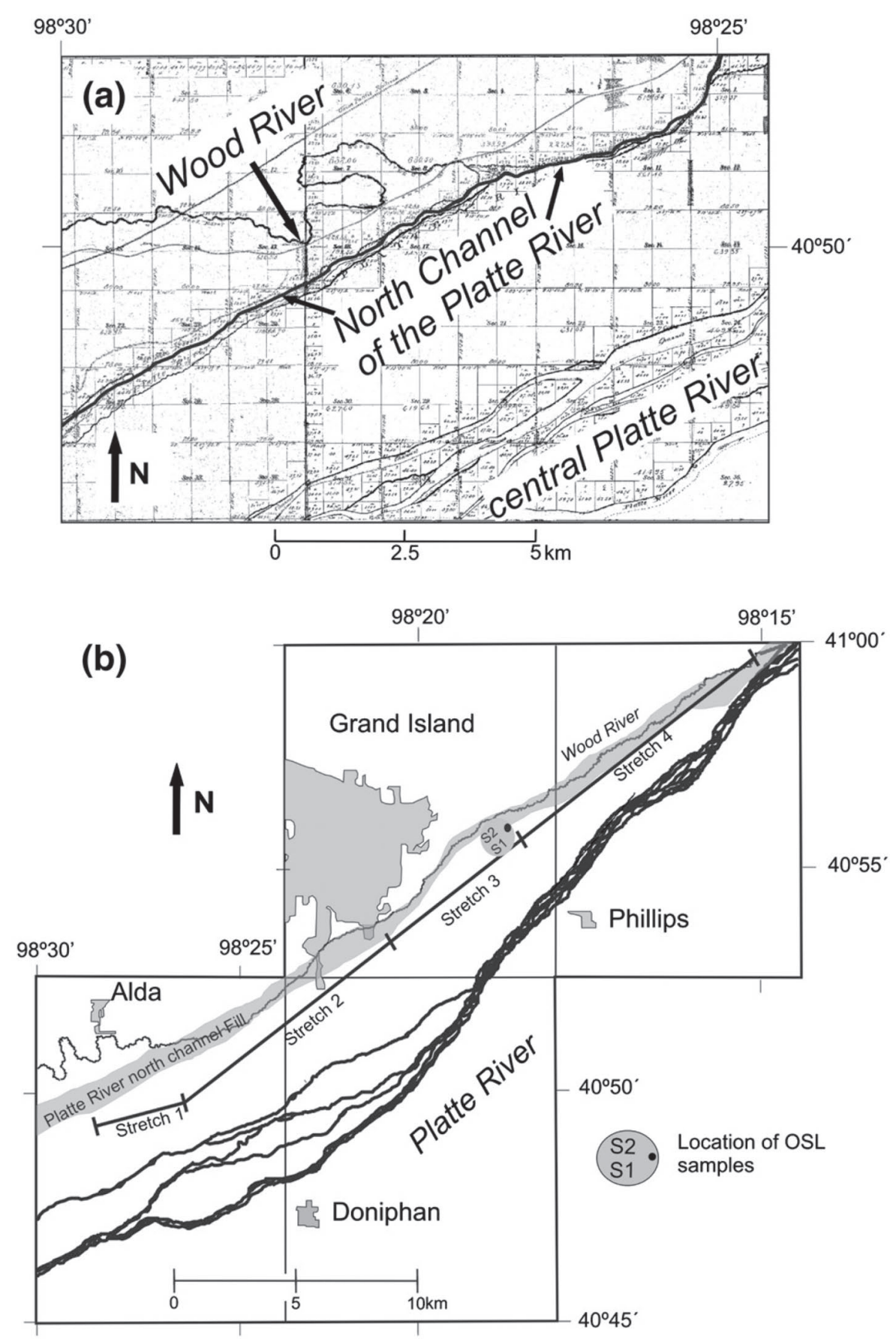

Figure 5. A and B) Location of Wood River convergence with the North Channel of the Platte River ca. 1880 based on General Land Office surveyor's maps. The North Channel at that point was a narrow, fairly straight stream. The Wood River channel in stretch 1 is superimposed on a meandering pattern from a larger stream system. Stretches 2, 3, and 4 have pirated the abandoned North Channel of the Platte River and flow through the older stream's alluvial fill (shaded brown). Stretches 2 and 3 mainly occupy the edges of the fill, while stretch 3 occupies the center of the fill. The S1 and S2 labels denote the location of OSL samples taken from the Platte River North Channel.

cupied an older braid belt to the north of the current course at least as early as $450 \pm 60$ years ago, on the basis of a date from a natural levee deposit, and that it probably began the process of abandonment $350 \pm 50$ years ago, according to the dating of channel deposits (Horn, 2010). During this time until the turn of the twentieth century, the meandering Wood River entered this channel $5 \mathrm{~km}$ south of Grand Island at $40^{\circ} 51^{\prime} 14^{\prime \prime}$ N. $98^{\circ} 24^{\prime} 58^{\prime \prime}$ W. During the turn of the twentieth century, the North Channel of the Platte River was abandoned and reoccupied by the Wood River, which now enters the former confluence of the North Channel and the main stream of the Platte River (Figure 1).
After it occupied the North Channel of the Platte River, the sinuosity of the Wood River progressively increased during the period 1938-1999. From 1938 to 1951, three of the four stretches (stretches 1-3) of the Wood River for which sinuosity was calculated (Figure 5), decreased in sinuosity from 1938 to 1951 (Figure 6). Stretch 4, in the center of the abandoned North Channel of the Platte River alluvial fill (Figure 5b), increased in sinuosity from 1.17 to 1.35 .

From 1951 to 1999, sinuosities in stretches 1-3 were constant, while the sinuosity of stretch 4 continued to increase. The sinuosity of stretch 4 , in contrast, increased from 1.35 to 1.46 . 


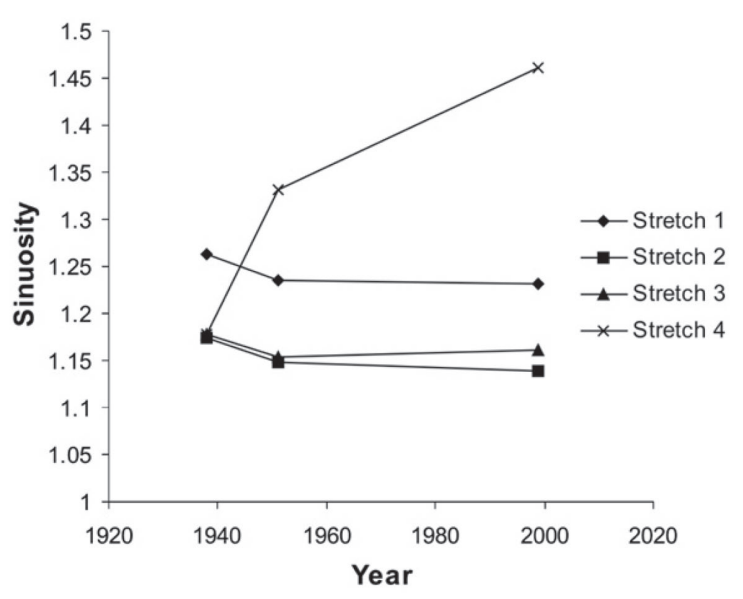

Figure 6. Changes in Wood River channel sinuosity from 1938 to 1999. Stretches 1-3 appear to have stabilized after an initial decrease between 1938 and 1958. The decrease from 1951 to 1999 in stretch 2 is anthropogenic channelization. By contrast, stretch 4 has increased dramatically from 1938 on.

By 1999, the sinuosities of stretches 2 and 3 were $\sim 1.17$ (Figure 6), which was slightly less than the sinuosity value of 1.2 for stretch 1 (Figure 6). Stretch 1 is upstream and outside of the North Channel of the Platte River, so its sinuosity was assumed not to have developed from a straight stream into a meandering stream post-1938. The current course of the Wood River in stretch 1 has a meander amplitude of $\sim 40-90 \mathrm{~m}$ and is superimposed onto an older set of larger meanders with a meander amplitude of $\sim 1 \mathrm{~km}$ and a sinuosity of 2.14 (Figure $5 \mathrm{~b}$ ). The uniformity of sinuosity in stretches 2 and 3 suggests that they had also become stabilized. Stretch 4, however, has increased markedly in sinuosity in the six decades between 1938 and 1999 (Figure 6) and preserves a meander belt, oxbow lakes, meander scars, and well-developed point bars.

\subsection{Shorter term (1984-2006) channel evolution in the Platte River}

The 26-year annual time series (1984-2009) shows a repetitive pattern in the formation and destruction of channel features that can be directly related to trends in average annual discharge (Figures 7-10). In both study areas, changes in discharge (Figure $7 \mathrm{~b}-\mathrm{e}$ ) were directly and positively correlated to occurrence of variations in channel width and area (Figure 7). However, the amount of change in width and area relative to discharge was not constant. In the more upstream section of the FSA sequence (area 1), changes were very slight: on the channel area and width graphs, channel change during both high flow periods (1984-1987; 1996-2001) created a curve with low slopes. The high flow periods of 1984-1987 and 1996-2001 also resulted in constant channel widths and areas (Figure $7 \mathrm{~b}$ $\& d)$, suggesting that the system was in some form of equilibrium. In contrast, changes in width and area were conspicuous in the downstream section (area 2: Figure 7c \& e). There was also an overall decrease in channel width across the time sequence in area 2, even though discharge rates from 1996 to 2001 were equal to or higher than those from 1984 to 1987.

These variations in width and area are related to the relative proportion of channel features and immobile islands (Figures 8-10). The following features can be identified in the aerial photograph series: (i) medium-size transverse bars, (ii) large transverse bars, (iii) open channels, (iv) exposed channel surfaces, (v) laterally accreted surfaces, and (vi) vegetated islands (Figure 11). The channel features recognized in the annual photographs (Figures $9 \& 10$ ) have been observed to form only when certain discharge thresholds were met (Figure 8). Channel features that formed during a certain flow threshold were found to be reworked or remobilized if those thresholds were exceeded or no longer met from one year to the next. Reworked features are those that were partially modified by changing flow conditions, whereas remobilized features underwent complete erosion through discharge fluctuations in the river.

\subsubsection{Medium-sized transverse bars}

Medium-sized transverse bars $(n=30$ observed in the time series) are transverse bars that formed broadly lobate planforms and occurred as isolated bars or in en echelon groups (Figure 9: 1988-1989, 1993, 1996; Figure 10: 1988; and Figure 11). These bars, which formed under similar annual average discharge regimes, ranged 40-93 $\mathrm{m}$ in length and 33-88 $\mathrm{m}$ in width (Figure 9: 1988-1989, 1993, 1996, Figure 10: 1988; and Figure 11). Medium-size transverse bars in the Platte River generally formed in under average annual discharges of 45$67 \mathrm{~m}^{3} / \mathrm{s}$ (Figure 8), and they were still present after discharges decreased to as low as $33 \mathrm{~m}^{3} / \mathrm{s}$, or as they increased to as much as $85 \mathrm{~m}^{3} / \mathrm{s}$ (Figure 8 ). At discharge rates below $33 \mathrm{~m}^{3} / \mathrm{s}$, the medium-size transverse bars were exposed and reworked by secondary channels that cut across them (e.g., Figure 9: 1990). At discharge rates above $85 \mathrm{~m}^{3} / \mathrm{s}$, the bars were reworked into channel bed features (e.g., Figure 9: 1994).

The appearance of medium-size transverse bars follows distinct sequences of formation that unfold over a period of two to three years. Specifically, these bars appear either (i) in years $(1988,1989)$ having average annual discharges of $48 \mathrm{~m}^{3}$ /s or less following higher discharge years (1987) that exhibited open channels (see forthcoming discussion; Figures $9 \& 10$ ); or (ii) after average annual discharge increased from $26 \mathrm{~m}^{3} / \mathrm{s}$ in 1992 in area 1 (Figure 9). Length to width ratios of all these barforms were $\sim 1.4: 1$.

\subsubsection{Large transverse bars}

Large transverse bars ( $n=20$ observed in the time series) are classified as those exceeding $90 \mathrm{~m}$ in width. These bars were the only macroforms present during the particularly high flow years of 1984, 1985, and 1997-2001 ( Figures 8 \& 11). Large transverse bars usually occurred as single, isolated bars nearly filling individual channels or as alternating bars, such as those described from the lower Platte River (Crowley, 1981; Figures 9 \& 10: 1984, 1985, 1997-2001; Figure 11). Large transverse bars range from 116 to $254 \mathrm{~m}$ in length and from 92 to $180 \mathrm{~m}$ in width, and they have length to width ratios of $\sim 1.3: 1$. During initiation of the large transverse bars, discharge rates ranged from 79 to $151 \mathrm{~m}^{3} / \mathrm{s}$ (Figure 8).

\subsubsection{Open channels}

Channels with no recognizable bars, vegetated islands, or visible channel bed features from bank to bank were classified as open channels (Figure 9: 1986-1987, 1995; Figure 10: 1987; and Figure 11). Independent ground-level observations indicate that three-dimensional subaqueous dunes or unit bars $\pm 1 \mathrm{~m}$ in height, as well as secondary channel scours and ripples, would have been present in the beds of these channels, even though submergence rendered them invisible in aerial photographs. Open channels occurred in the two years $(1986,1987)$ following the high discharge year of 1985 (Figures $9 \& 10$ ) and in 1994 and 1995 preceding the high discharge years of 19972001. In 1985, average annual discharge was $79 \mathrm{~m}^{3} / \mathrm{s}$, and average annual discharge during the period 1997-2001 ranged from $67 \mathrm{~m}^{3} / \mathrm{s}$ to $86 \mathrm{~m}^{3} / \mathrm{s}$ (Figure 8 ). Large transverse bars formed during the high flow event in 1985 were reworked in the lower discharge year of 1987, which averaged $77 \mathrm{~m}^{3} / \mathrm{s}$ (Figure 8). There is photographic evidence of the reworking of the large transverse bars from 1997 to 2001, even though discharge decreased to $35 \mathrm{~m}^{3} / \mathrm{s}$.

Open channels also occurred in certain years in channels featuring large individual vegetated channel islands (Figure 10: 1993-1996). 
(a)

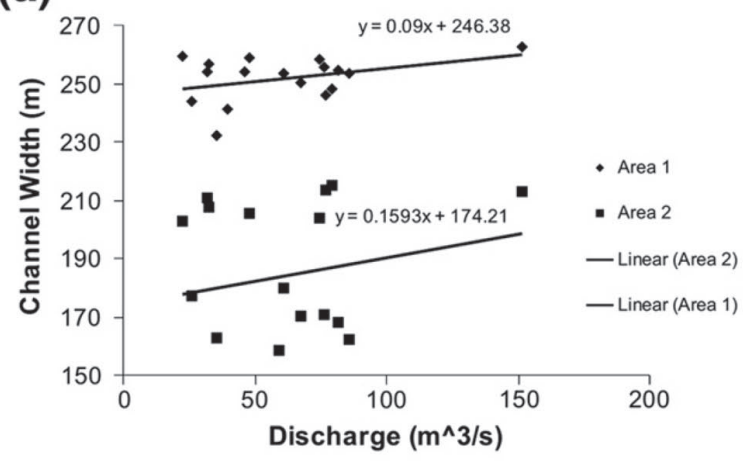

(c)
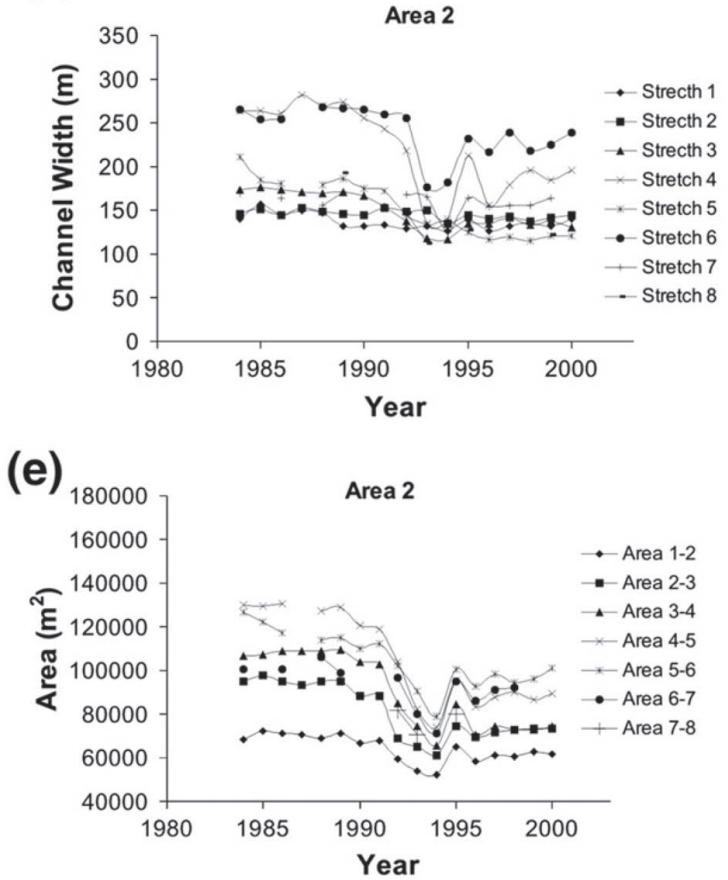

(b)

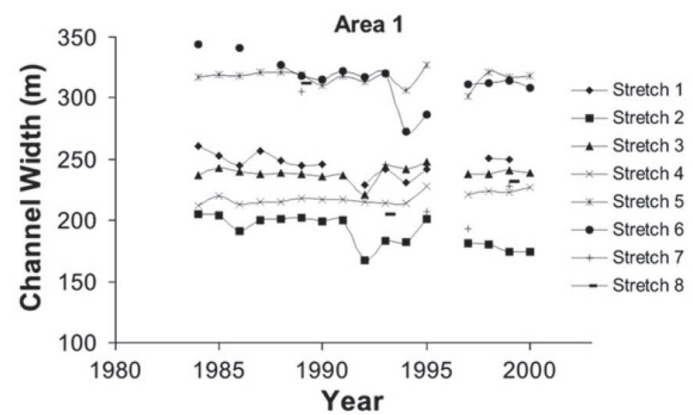

(d)

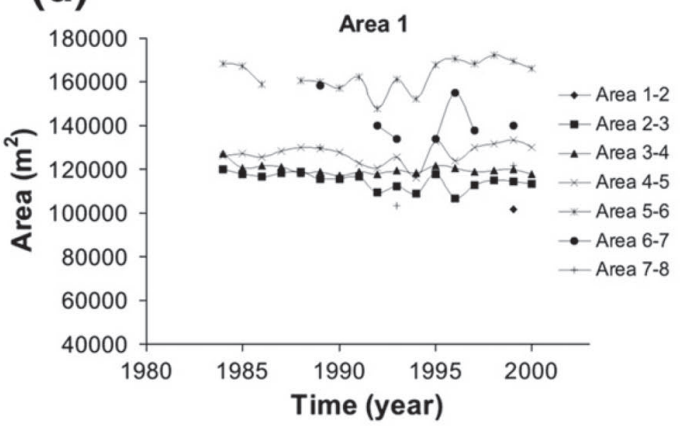

(f)

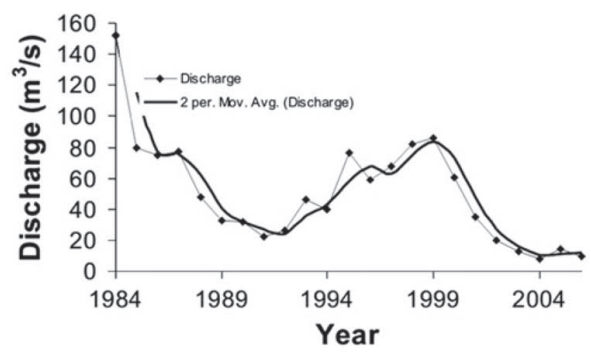

Figure 7. a) Comparison of average annual discharge values to channel width for Platte River for the years 1984-2001 in areas 1 and 2 shown in Figure 3. b and c) Channel width, and $\mathrm{d}$ and e) area variations as a function of time for areas 1 and 2 . Area 1 shows a slight dip in width and area after the lowest flow year, from 1992 to 1995; but is otherwise fairly uniform throughout the sequence. Area 2 has a more pronounced decrease in area and width from 1991 to 1995 . However area 2 does not attain widths and channel area reached in the previous high flow period. f) Channel discharge in the western part of the study area from 1984 to 2001. Discharge shows high flow periods from 1984 to 1987 and 1994 to 2001 . USGS gauge location in Figure 1.

\subsubsection{Exposed channel surfaces}

Exposed channel surfaces occurred during very low discharge years (e.g., 1989-1992) when flow ceased in channels, and channel floors and bars were subaerially exposed (Figure 9:1990-1992; Figure 10: 1989-1990; and Figure 11), typically when average annual discharge dropped below $32 \mathrm{~m}^{3} / \mathrm{s}$ (Figure 8).

\subsubsection{Laterally accreted surfaces}

Laterally accreted surfaces $(n=9$ observed in the time series) occurred very rarely around large-scale transverse bars and vegetated channel islands (Figure 11). Laterally accreted surfaces ranged from 21 to $102 \mathrm{~m}$ in length and 10 to $22 \mathrm{~m}$ in width, with areas ranging from 212 to $1387 \mathrm{~m}^{2}$.

\subsubsection{Vegetated channel islands}

Inactive channel bars stabilized by vegetation are classified as vegetated channel islands ( $n=30$ observed in the time series). These islands separate second-order anabranches. Vegetated channel islands were observed to form and expand during low discharge periods (Figure 8; Figure 10: 2006-2009; Figure 11: 1991, 2006-2009; and Figure 12). Vegetation was observed to have expanded across exposed channel surfaces when average annual discharge was lower than $22 \mathrm{~m}^{3} / \mathrm{s}$ (e.g., 2006; Figure 8). Vegetated islands ranged from 7 to $405 \mathrm{~m}$ in length and from 3 to $91 \mathrm{~m}$ in width, with areas ranging from 20 to $10,795 \mathrm{~m}^{2}$.

\section{Discussion}

\subsection{Longer-term channel change}

\subsubsection{Platte River}

The most visible historical change in the central Platte River ecosystem since 1858, the date of the first General Land Office (GLO) survey map, has been an overall decrease in bankfull channel dimensions (cf. Williams, 1978; Eschner, 1983; Eschner et al., 1983; Johnson, 1994; Johnson and Boettcher, 1999; Joeckel and Henebry, 2008). Channel constriction, from the construction of dams and diversion canals for irrigation, and encroachment of riparian vegetation into formerly open channels, 


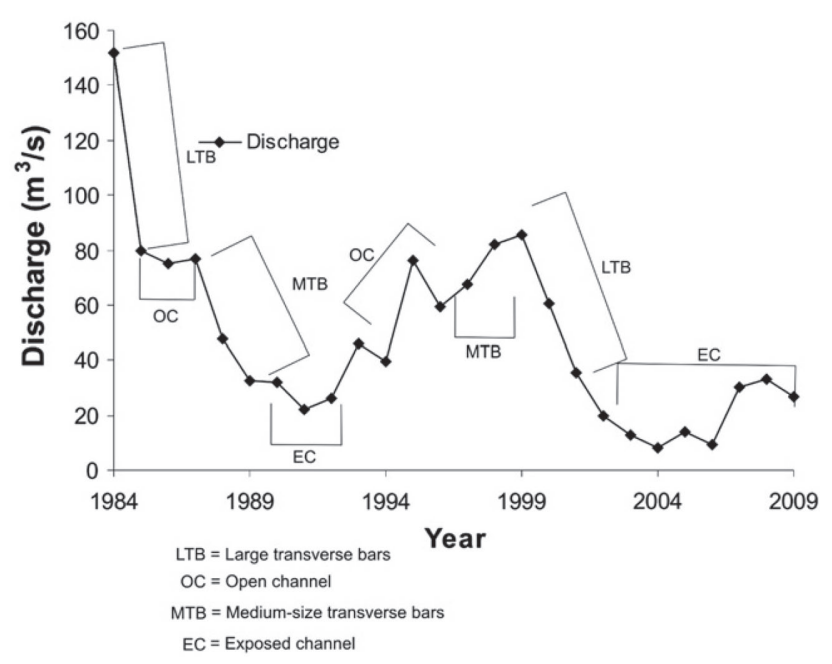

Figure 8. Time ranges of channel feature inception and disappearance overlain on plots of yearly discharge values in area 1 from 1984 to 2006 .

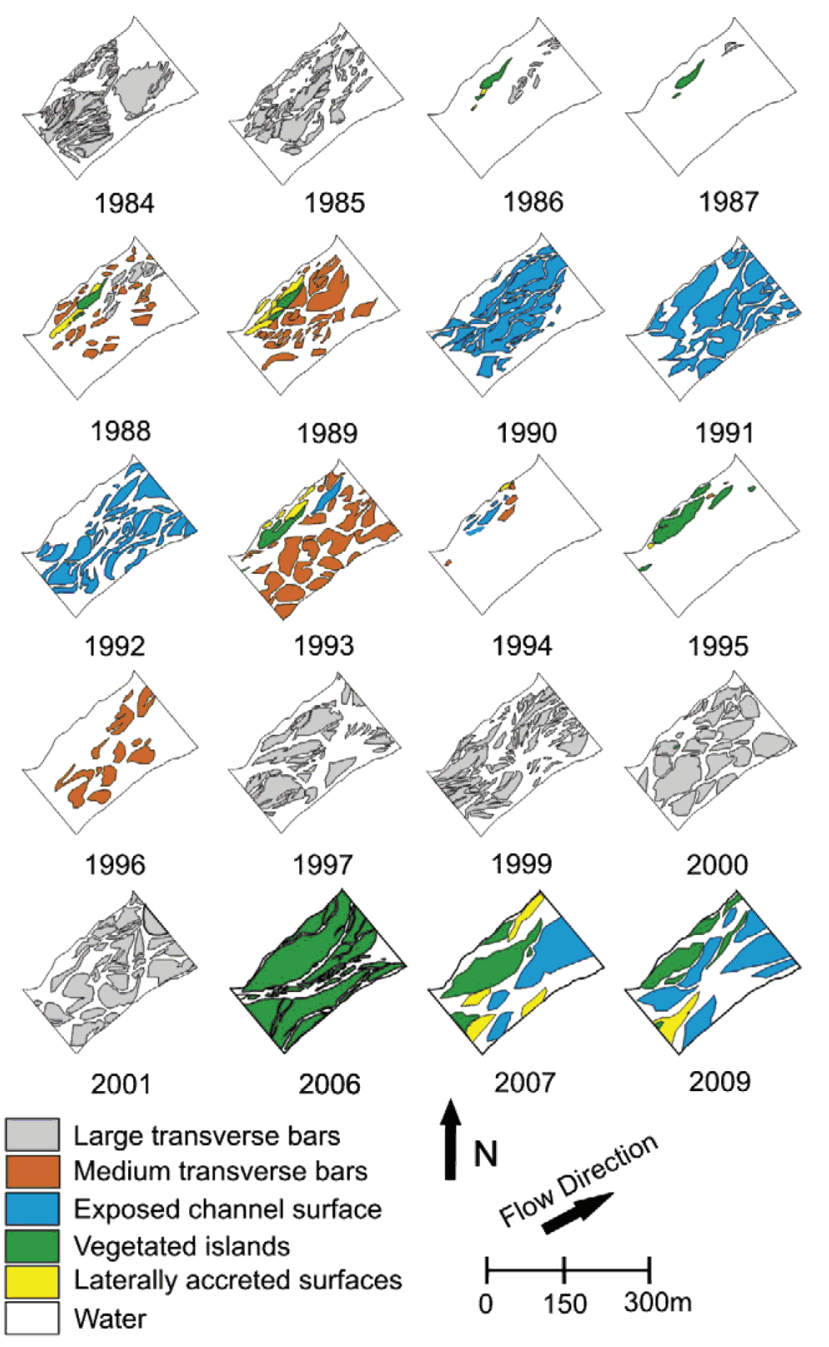

Figure 9. Characterization of changes in channel feature occurrence in Area 1 over the time interval 1984-2009. Similar types of bar and channel features can be found in both study areas until 1999. After 1994, area 1 repeated the pattern seen in the 1984-1990 sequence. Modified from Horn et al. (in press). have been shown to be primarily responsible for these changes (Johnson, 1994; Osterkamp and Hupp, 1996; Johnson and Boettcher, 1999; Thoms and Sheldon, 2000; Bennett and Simon, 2004). Damming and flow diversion through canals along the river led to the stabilization of bars and the shrinkage of channels (Johnson, 1994; Joeckel and Henebry, 2008).

Decreases in channel width and area discussed by Joeckel and Henebry (2008) in the lower Platte River were documented herein from the central Platte River based on similar data. The 1999 channel is roughly half the size of the channel in 1953, even though discharge rates were twice as high in 1999 as they were in 1953. On a timescale of tens of years, channel area and width from 1938 to 2006 steadily decrease. A slight increase in channel dimensions in stretch 3 during 2006 may have resulted from the reduced stabilization of islands from to desiccation of plant material during the 2006 drought allowing for some reworking and mobilization along the edges of some islands and banks. Furthermore, channels and bars that were abandoned were vegetated within one to two years. Observations of steady abandonment coeval to vegetation of channel beds led to the inference that channel abandonment along all stretches of the Platte was the stabilization of bars and above-water channel beds through the establishment of grassy and woody vegetation. The decrease in channel area despite an increase in discharge supports the con-

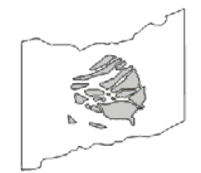

1984

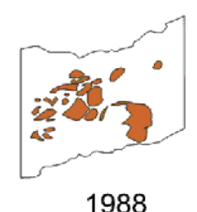

1988

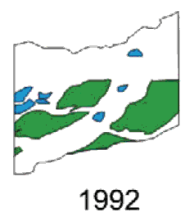

1992

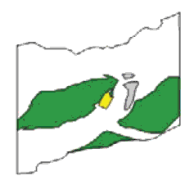

1996

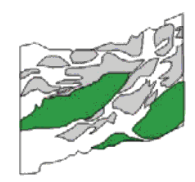

2001

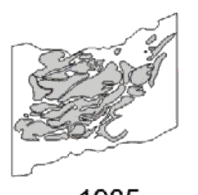

1985

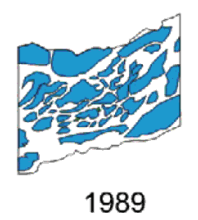

1989

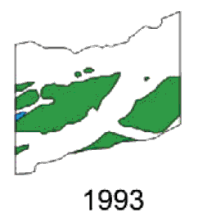

1993

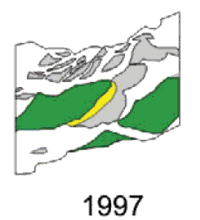

1997

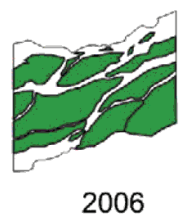

Large transverse bars

Medium transverse bars

Exposed channel surface Vegetated islands Laterally accreted surfaces Water
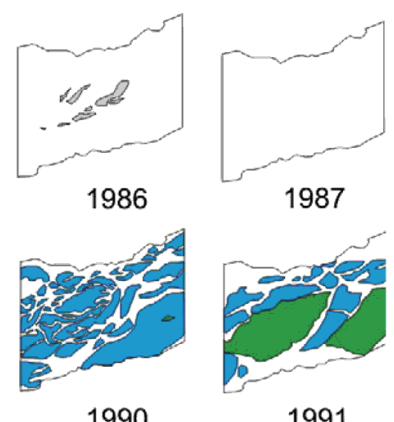

1991
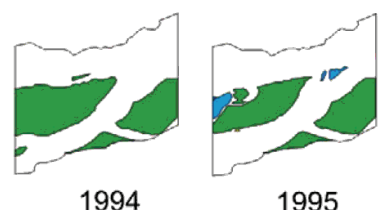

1995

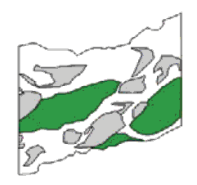

1999

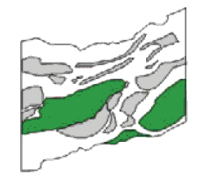

2000

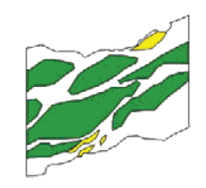

2007

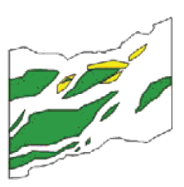

2009

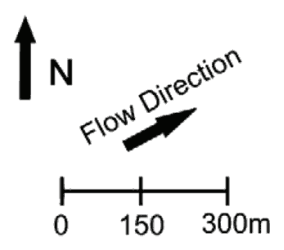

Figure 10. Characterization of changes in channel feature occurrence in area 2 over the time interval 1984-2009. Both areas exhibit similar shifts in barform prevalence throughout the time series. Similar types of bar and channel features can be found in the study area until 1994. After 1994, area 2 became dominated by large vegetated islands. 
1

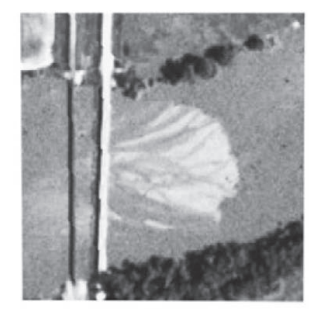

Large transverse bars

3

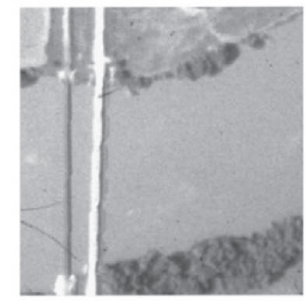

Open-water channel

5

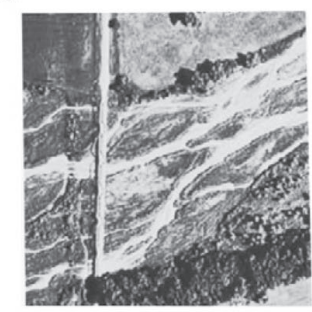

Vegetated islands
2

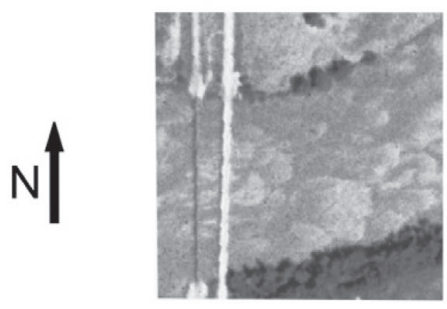

Medium transverse bars

4

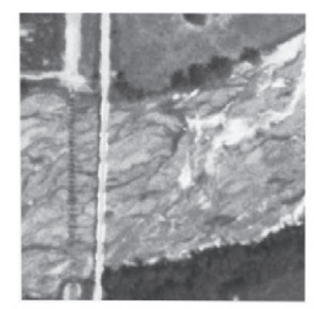

Exposed channel surface

6

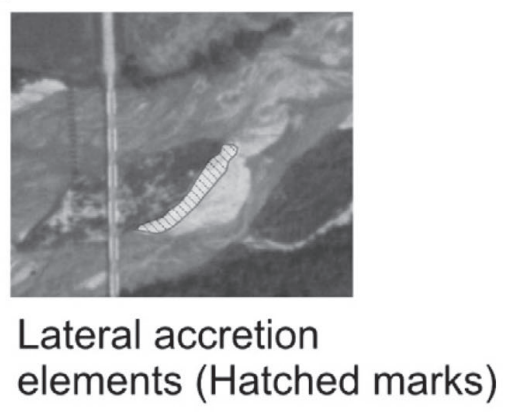

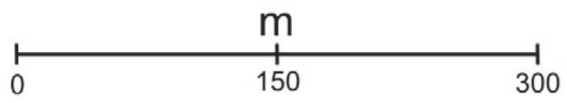

Figure 11. Examples of channel features observed in the study areas from 1984 to 2009, all taken from area 2.

clusion that the decrease was due to vegetation growth and stabilization on channel islands and channel banks leading to increased entrenchment of the channel and was not primarily controlled by average annual stream discharge. The increase in channel area from 1993 to 1999 reflects the remobilization of exposed channel bedforms and vegetated islands into medium and large transverse bars (Figure 4) due to a short-term $(\sim 5$ years $)$ increase in discharge.

\subsubsection{Wood River}

The presence of scroll bars in stretch 1 of the Wood River at the same scale as the larger meander patterns strongly suggests that the ancestral Wood River carried higher discharges prior to the first GLOs in the $1860 \mathrm{~s}$. The presence of overprinted ancestral meanders downvalley of the Wood River with a similar scale of meandering suggests that the two streams may have been part of the same system (see passage on Warm Slough in Horn, 2010) that date from $1080 \pm 100$ years ago.

\subsection{Shorter-term channel change}

Examination of an annual time series provides a new and more detailed perspective on braided-stream channel constriction and planform change. Channel area and width values, as well as the inception of second-order anabranches, exhibit greater dependence on discharge in the shorter term 19842001 annual photos (Figure 7) than in the longer term 19382001 aerial series (Figure 4). The overall trend of narrowing in the longer term sequence despite variations in discharge is likely the encroachment of woody vegetation, which has been too gradual to be a significant influence on channel width on a year-to-year basis as discharge. The two shorter term channel change study reaches (Figure 3) display similar coeval responses to changes in flow rate by channel and bar forms, suggesting a predictable response by the river to different flow regimes (Figures $9 \& 10$ ).

- Because of the higher energy flow regimes in which large transverse bars formed, they were rapidly reworked by secondary channels, each trending roughly parallel to the main axis of flow, after discharge decreased and the bars were exposed. Therefore, when discharge was decreased to $79 \mathrm{~m}^{3} / \mathrm{s}$, these large bars were completely reworked by secondary channels and their sediments were incorporated into channel bedforms (Figure 11).

- The lack of any surficial channel bars during years of rising discharge (46 to $76 \mathrm{~m}^{3} / \mathrm{s}$; Figure 8 ) may have been caused by a combination of channel deepening resulting from lateral constriction (cf. Johnson, 1994) and the instability of the 


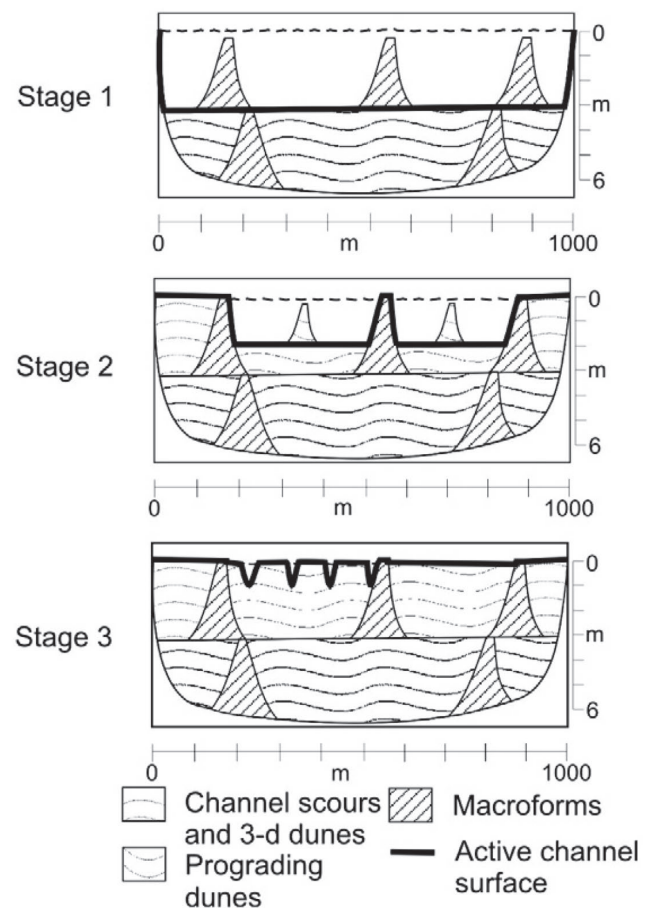

Figure 12. Channel abandonment model to account for the gradual abandonment of the Platte River braided stream system and its evolution from a braided to an anabranching system. Stage 1: channel features macroform bars comprising downstream-migrating foresets. Stage 2: downstream-migrating dunes are deposited over channel bed features. Stage 3: the channel is dominated by anabranches and only channel bed features are present.

secondary channel-scale, medium-size transverse bars at average annual discharge rates exceeding $67 \mathrm{~m}^{3} / \mathrm{s}$ (Figure 8).

- During early stages of channel exposure, higher flow regime barforms were exposed and then gradually reworked by secondary channels flowing roughly parallel to the primary channel (e.g., Figure 9: 1989). As discharge rates began to increase, the secondary channels became more sinuous (Figure 9: 1992). These secondary channels widened as discharge levels continue to rise and ultimately led to the development of the exposed interchannel surfaces into medium-size transverse bars (Figure 9: 1993).

- Laterally-accreted surfaces were found to form by the interception of migrating barforms by immobile bars and islands during periods of high discharge (Figure 9: 1988-1989, 1993, 1995; Figure 10: 1996-1997). During decreased flow periods, lateral accretion deposits were reworked or remobilized by secondary channels or became parts of vegetated islands.

- The majority of vegetated islands formed during the period 1984-1999 (Figures 9 \& 10) were reworked when average annual discharges exceeded $86 \mathrm{~m}^{3} / \mathrm{s}$ (Figure $8 \mathrm{~A}$ ). Vegetated islands, however, again dominated the channels by 2006 and continued to dominate through 2009.

The following is the interpreted sequence of responses of bar and channel forms to different flow regimes. During the High flow year of 1984 with discharge rates above $79 \mathrm{~m}^{3} / \mathrm{s}$ (Figure 8) flow was competent enough to form large transverse bars. The following years of decreased discharge (1985-1987) (Figure 8), the bars became reworked by less competent secondary channels and were subsequently degraded to the point that no transverse bars existed within the channel (Figures 9-11). During higher-low flow transitions, medium-size transverse bars formed within open channels (Figure 9: 1988-1989 Figure 10: 1988; and Figure 11). After channel discharges decreased, the bars became part of the exposed channel bottom and were reworked by secondary channels (Figure 9:1990-1992; Figure 10:
1989-1990; and Figure 11). As flows began to transition from low to high, secondary channels became increasingly sinuous and transverse to flow, carving out barforms similar in size and shape to medium transverse bars by 1993 . Increasing channel discharge remobilized the bars; and during high years such as 1995 (Figure 8), the bars were temporarily combined into large transverse bars (Figure 11). Steadily increasing flows also led to the formation of large transverse bars from medium transverse bars, but continual increases began to accrete large bodies of sand laterally onto vegetated islands, such as those found in area 2 (Figure 10:1991-2006). In the low discharge years after 2000 (Figure 8) the partially-reworked large transverse bars were stabilized by vegetation upon exposure, protecting them from further destruction. A more rapid decrease in average discharge rates in 2001-2006 than had occurred in 1985-1992 (Figure 8) resulted in the absence of the open channel and transitional phase and led to a prevalence in vegetated islands not seen before in the period 1984-2009.

Discharge rates of the Platte River during the period 19842009 exhibited two episodes of high and low flow (Figure 8), but a similar pattern could not be placed on the formation and evolution of the vegetated channel islands, which had expanded through low as well as high discharge phases (Figure 10: 1991-2006). The occurrence of exclusively large transverse bars in the channel in the 1984-1987 high flow period (Figures 9 \& 10) was not duplicated in the 1996-2001 high flow period, which exhibited both large transverse bars and vegetated islands (Figures $9 \& 10$ ). The lack of a direct relationship with discharge in the channel after 1996 may have been linear changes in vegetation type, and it has been reported that invasive grasses became increasingly prevalent in the Platte River valley (Walters, 2010). The establishment of these invasive grasses on exposed channel surfaces during low flow periods could have stabilized bars into vegetated islands. Beginning at least as early as 2006, the channel islands of Area 1 were ploughed by the Platte River Whooping Crane Trust to remove all vegetation. As a result, many of the vegetated channel islands that formed in 2006 in area 1 reverted to exposed channel surfaces, with prominent laterally accreted surfaces, by 2009 (Figure 9: 2007, 2009). In area 2 and elsewhere where the channel islands were not ploughed, the only channel features were vegetated islands (Figure 10: 2007, 2009).

\subsection{Channel abandonment}

On the decadal scale, the channel morphologies of many stream systems have been significantly affected by the creation of dams, irrigation systems, and by land use changes since 1900 (Williams and Wolman, 1984; Johnson, 1994; Johnson and Boettcher, 1999). Throughout the early 1900s, diversion dams including Kingsley (1941), Pathfinder (1909), Glendo (1958), Guernsey (1928), Alcova (1938), and Seminoe (1939) were created to take advantage of spring flows and to divert those flows into large canal systems (Figure 1). In addition, extensive damming on the North Platte River reduced sediment influx into the Platte River by about 50\% from 1895 to 1999 (Simons and Associates, Inc., 2000).

A reduction in annual bankfull discharge flows from damming and canalization has led to the establishment of channel bars and banks of riparian vegetation. In some subtropical streams, riparian vegetation stabilizes exposed channels during the dry season (e.g., Fielding et al., 1997; Nakayama et al., 2002; Tooth et al., 2008). Although the central Platte River is not as seasonally dynamic as some of these streams, it has fluctuated from years with very high discharge years to years with almost no discharge within a decade (e.g., 1999 vs. 2006). The cessation of flows during the dry intervals has allowed dense riparian vegetation, cottonwoods (Populus sp.), and willows (Salix sp.) to become established. The invasive reed Phragmites australis has more recently become established in the 
Platte River during a 7-year drought that began in 2001 (Figure 8; Hack et al., 2009) and continues to spread from changes in sediment supply resulting from discharge reduction (Hansen, 1978; Marks et al., 1994; Saltonstall, 2002).

At the time of Euramerican settlement, the river comprised multiple anabranches, including its currently active channels and the now-abandoned North Channel of the Platte River. Since the mid-nineteenth century, and particularly from 1938 onward, most of the Platte River has progressively narrowed and its channel surface area has decreased markedly. These changes have accelerated in the central Platte River since 1999. As a result of this narrowing, over half of the central Platte River channel was stabilized and abandoned during the period 1858-2006. The lower Platte River has not undergone channel narrowing as intensely as the central Platte River from the influence of tributaries, but it has still undergone a change in bar-forming processes related to a decrease in sediment and water discharge (Horn et al., in press).

The central Platte River channel abandonment model presented in this paper quantifies and characterizes the processes involved in channel filling of the central Platte River (Figure 12) and represents one of the first attempts to characterize evolution of macroforms in a sandy braided stream through direct observation of ongoing processes. The subsurface structure of the first two stages is based on subsurface analysis of bars within inactive (stage 1) and active lower Platte River (stage 2) channels, as described in Horn et al. (in press), while the third stage (stage 3 ) is based on surface and subsurface descriptions of the central Platte River. During stage 1 (Figure 12), the channel is dominated by downstream migrating, planar cross-beds, from medium-size and large transverse bars, overlying secondary channel scours and dunes. This stage is similar to conditions that would have been visible in the late 1990s in the central Platte River. Stage 2 (Figure 12) is characterized by the presence of bars comprising mainly trough cross-strata of downstream-migrating dunes $\sim 2 \mathrm{~m}$ thick overlying secondary channel scours and dunes. In stage 3 (Figure 12), the river is dominated by channel bedforms: secondary channel scours, subhorizontal strata, and trough crossbedding. Bars are no longer formed in stage 3, and channels become increasingly constricted and incised leading to the development of second-order anabranches.

\section{Summary and conclusions}

Our work identifies fluvial system changes in the Platte River across different time scales. The mean channel area of the central Platte River decreased by an average of $46 \%$ from 1938 to 2006, and the mean widths of the individual channels in 1858 were $539 \%$ greater than in 2006. This decrease in area and width coincides with the encroachment of vegetation from channel banks and vegetated islands after the construction of dams and diversion canals. In light of its high variability over longer term time scales, stream discharge apparently took a secondary role to that played by encroaching vegetation, which protected banks and islands from remobilization once established during low flow periods. During this same time interval, The Wood River increased in sinuosity after 1938 and is partially superimposed on an ancestral meandering pattern that must have carried a greater average discharge.

In contrast to secondary role of annual discharge on the overall decrease in Platte River channel width between 1938 and 2006, observations on shorter time scales show a greater dependence of channel width on discharge. This dependence can be attributed to the occurrence or absence of in-channel features, such as: medium-size transverse bars, large transverse bars, open channels, exposed channel surfaces, laterally accreted surfaces, and vegetated channel islands. The vege- tated mid-channel islands now present within the active central Platte River may be similar to macroforms found in other braided stream systems that have been affected by the encroachment of vegetation. Such encroachment occurs during lower discharge years and continues into years of higher discharge.

Clearly, the most obvious of these changes have taken place during late historic times as the river continues to respond to anthropogenic effects. Nonetheless, evidence exists for change predating Euramerican settlement (ca. 1854), such as the dwindling of flow in the North Channel of the Platte at the time of the GLO surveys, the reduction of meander scale and incision on the Wood River, and the possible evolutionary relationship between the Wood River and Warm Slough in the Grand Island area. Collectively, these observations reveal that the Platte River was a dynamic stream in the recent geologic past, well before Euramerican settlement.

Our analysis of the change in the Platte River also includes the first direct and detailed observations of the abandonment of a braided channel. In a system unaffected by anthropogenic change, similar processes likely would unfold over a timescale exceeding that of direct human observation. Our observations are made possible because a relatively rapid decrease in channel area and width occurred on the central Platte River over a mere seven decades. In stage 1 , the channel prominently features macroform bars comprising downstream-migrating foresets. Stage 2 comprises downstream-migrating dunes deposited over channel bed features. Finally, in stage 3, there is a shift from a braided stream to a stream dominated by secondorder anabranches, only channel bed features are present.

Our new channel abandonment model for braided streams provides an intimate understanding of not only the internal and planform characteristics of a stream that has already been abandoned, but also of channel and planform features that form and dissipate during the process of abandonment, as well as the chronological sequence of these features. Thus, it will be possible to interpret a series of events from abandoned channels in the sedimentary record, and to be able to predict the next phase in channel evolution of a channel that either may become abandoned or is in the process of abandonment.

Acknowledgments - This study was funded under a U.S. Geological Survey STATEMAP Cooperative Geologic mapping to R. M. Joeckel and three UNL Department of Geosciences summer fellowships. The first author would also like to acknowledge the support of a number of organizations for providing and processing the data utilized in this study: the UNL conservation and Survey Division, the Nebraska Department of Natural Resources, the UNL School of Natural Resources, the Bureau of Land Management, and the USDA Farm Service Agency.

\section{References}

Bennett, S. J., Simon, A. (eds.), 2004. Riparian Vegetation and Fluvial Geomorphology: Water Science and Application, 8 (Washington DC).

Bridge, J. S., 2003. Rivers and Floodplains: Forms, Processes, and Sedimentary Record. Blackwell Publishing, Oxford, UK.

Crowley, K. D., 1981. Large-Scale Bedforms in the Platte River Downstream from Grand Island, Nebraska - Structure, Process, and Relationship to Channel Narrowing. U. S. Geological Survey, Washington DC. (Open-File Report 81-1059).

Eschner, T., 1983. Morphologic changes in Platte River channels. U. S. Geological Survey Professional Paper, Washington DC.

Eschner, T., Hadley, R. F., Crowley, K. D., 1983. Hydrologic and morphologic changes in channels of the Platte River Basin in Colorado, Wyoming, and Nebraska; A historical perspective. U. S. Geological Survey Professional Paper, Washington DC (A1-A39 pp.). 
Fielding, C. R., Alexander, J., Newman-Sutherland, E., 1997. Preservation of in situ, arborescent vegetation and fluvial bar construction in the Burdekin River of north Queensland, Australia. Palaeogeography, Palaeoclimatology, Palaeoecology 35, 123-144.

Hack, M., Kearney, R., Smith, C., Taylor, S., Allen, C., 2009. Invasions and Extinctions as a Consequence of Climate Change. Office of Research and Economic Development Publications, University of Nebraska-Lincoln.

Hansen, R. M., 1978. Shasta ground sloth food habits, Rampart Cave, Arizona. Paleobiology 4, 302-319.

Horn, J. D., 2010. Fluvial evolution of the central Platte River sand body near Grand Island, Nebraska. PhD dissertation, University of Nebraska-Lincoln, Lincoln, NE.

Horn, J. D., Fielding, C. R., Joeckel, R. M., in press. Revision of Platte River alluvial facies model through observations of extant channel and barforms, and subsurface alluvial valley fills. Journal of Sedimentary Research.

Joeckel, R. M., Henebry, G. M., 2008. Channel and island change in the lower Platte River, eastern Nebraska, USA: 1855-2005. Geomorphology 102, 407-418.

Johnson, W. C., 1994. Woodland expansion in the Platte River, Nebraska: Patterns and causes. Ecological Monographs 64, 45-84.

Johnson, W. C., Boettcher, S. E., 1999. Restoration of the Platte River: What is the target? Land and Water 20-23 (May/June).

Marks, M., Lapin, B., Randall, J., 1994. Phragmites australis (P. communis) threats, management, and monitoring. Natural Areas Journal 14, 285-294.

Murphy, P. J., Randle, T. J., Fotherby, L. M., Daraio, J. A., 2004. The Platte River channel: History and Restoration. Bureau of Reclamation, Denver, Co. (177 pp.).

Nakayama, K., Fielding, C., Alexander, J., 2002. Variations in character of preservation potential of vegetation-induced obstacle marks in the variable discharge Burdekin River of north Queensland, Australia. Sedimentary Geology 149, 199-218.
National Academy of Sciences, 2004. Endangered and Threatened Species of the Platte River. The National Academies Press, Washington, DC.

Osterkamp, W. R., Hupp, C. R. (Eds.), 1996. Fluvial geomorphology and vegetation: Geomorphology, 14, pp. 275-351.

Saltonstall, K., 2002. Cryptic invasion by a non-native genotype of the common reed, Phragmites australis, into North America. Proceedings of the National Academy of Sciences of the United States of America 99, 2445-2449.

Simons \& Associates, Inc, 2000. Physical History of the Platte River in Nebraska: Focusing Upon Flow, Sediment Transport, Geomorphology, and Vegetation. Simons \& Associates, Inc., Fort Collins, CO.

Thoms, M. C., Sheldon, F., 2000. Australian Lowland Rivers: Regulated Rivers: Research and Management, 16, pp. 375-383.

Tooth, S., Jansen, J. D., Nanson, G. C., Coulthard, T. J., Pietsch, T., 2008. Riparian vegetation and the late Holocene development of an anabranching river: Magela Creek, northern Australia. Geological Society of America Bulletin 120, 1021-1035.

Walters, S., 2010. Carbon dynamics in a Phragmites australis invaded riparian wetland. M. S. thesis, University of Nebraska-Lincoln, Lincoln, NE.

Williams, G. P., 1978. The case of the shrinking channels - the North Platte and Platte Rivers in Nebraska. U. S. Geological Survey Circular, 781 (Arlington, VA).

Williams, G. P., Wolman, M. G., 1984. Downstream effects of dams on alluvial rivers. U. S. Geological Survey Professional Paper, 1286 (Washington, DC). 